\title{
Sustainable Wine Scoring System (SWSS): A life cycle assessment (LCA) multivariable approach
}

\author{
A.E. Valero ${ }^{1}$, J.A. Howarter ${ }^{1,2}$, and J.W. Sutherland ${ }^{1}$ \\ ${ }^{1}$ Environmental and Ecological Engineering, Purdue University, Indiana, USA \\ ${ }^{2}$ Material Engineering, Purdue University, Indiana, USA
}

\begin{abstract}
Sustainable practices have become accepted by a large part of the wine community as a necessary step to face climate change challenges and natural resources depletion. Also, in recent years, there is a rising influence of sustainability on consumer's buying decision. However, buyers fail to distinguish sustainable attributes from wine that is promoted under different sustainability labels. Moreover, wineries find it challenging to quantify the improvement of their environmental impact when following a specific sustainable practice. The objective of this study is to evaluate the methodology for the development of a Sustainable Wine Scoring System (SWSS). The SWSS aims to be a single numeric index of the sustainable attribute of a bottle of wine, constituted by multiple normalized indicators. Our initial approach for the SWSS is to quantify different environmental impact categories following a Life Cycle Assessment (LCA), to then normalizes and weighs the result regarding a reference region. We used as a case of study "Craft Wineries" in Indiana in the USA, as a non-traditional winemaking area. The impact assessment was conducted using SimaPro8.5 in accordance to TRACI2.1 for the USA. As result of our LCA, grape growing is the process that contributes the most to the ecotoxicity, non-carcinogenic, and eutrophication impact categories, while transportation stages contribute the most to global warming potential, smog, and ozone depletion. The calculated SWSS results vary from 279 for the scenario with the highest environmental impact to 350 for the best performance scenario. The SWSS has the potential to represent sustainable attributes of wine in a more suitable way than a single isolated indicator such as carbon footprint.
\end{abstract}

\section{Introduction}

During the last decades, sustainability has become a trending topic for government agencies, academics, companies, and international organizations [1]. The issue of sustainability raises significant implications for the wine industry. Sustainable practices have become accepted by a large part of the wine community as a necessary step to face climate change challenges [2] and natural resources depletion. In addition, in recent years, sustainability has had a growing influence on consumer's buying decision $[3,4]$. The percentage of consumers looking for sustainable attributes when buying wine has reached $30 \%$ of the total in many wine markets like the USA [5] and Germany [6]. This tendency is expected to increase due to the changing demographics of wine consumers [7], especially considering the notorious influence that "Millennials" will start having on the market during the next decade.

Accordingly, principal wine regions have adopted voluntary programs that identify and promote best practices for sustainable grape growing and winemaking. Most of these programs are voluntary and based on self-assessment tools. In addition, many programs have developed certification schemes and awarded sustainable labeling using third-party evaluations. Nonetheless, when looking at the sustainable attributes of a bottle of wine, consumers face numerous obstacles. Despite consumers" appreciation for "sustainable viticulture," evidence suggests they do not fully understand the practices a winery must follow to be cataloged as sustainable. While nine out of ten wine consumers from California interviewed by Zucca et al. (2009) thought that sustainable practices are essential for wine production only one out of ten identified companies that follow sustainable values [8]. A similar conclusion was reached by Gino et al. (2014) for French consumers. Even wine connoisseurs from Burgundy, in France, could not recognize the different sustainable attributes of wines labeled as organic, biodynamic, or sustainable [9]. The lack of familiarity with the different labeling related to sustainability and the practices they involve hinder the evaluation of the added value of sustainable attributes to the eyes of wine consumer and their wiliness to pay for it. In the same way, many grape growers and winemakers find it challenging to quantify the improvements in their environmental impact when following a specific sustainable practice and its implementation cost.

Most of the sustainability certification schemes in the wine sector are base on qualitative assessments. Hence comparisons among programs, sustainable practice, and attributes are problematic. Migrating from a qualitative approach to a quantitative one requires a unified procedure to fairly benchmark products, wineries, and regions. Each wine region has a unique ecosystem that is reflected in the identity of their products. If only one parameter became an extended sustainability indicator for all regions, such as a carbon footprint [10], trade distortion could be generated. For instance, wine from California sold in New York may 
be considered less sustainable than a French wine sold in the same city, regardless of the sustainability efforts of the wineries producing it, due to the emissions during transportation [11]. Moreover, greenhouse gases emission represent only the global impact of operation but not its regional impact.

The objective of this study is to evaluate the methodology for the development of a Sustainable Wine Scoring System (SWSS). The SWSS aims to be a single numeric index of the sustainability attributes of a bottle of wine, and is based on multiple normalized indicators. Our initial approach for the SWSS is to quantify different environmental impact categories following a Life Cycle Assessment (LCA) methodology. Life Cycle Assessment (LCA) is a methodology that can support decision-making regarding sustainability in the industry while facilitating communication. Previous LCA studies have evaluated the environmental performance of different stages of wine production. When comparing grape growing under different viticulture techniques in regions of Spain [12], Italy [13], and the USA [14], it can be noticed that even practices considered to be environmentally friendly such as organic farming, may not always be the best choice when considered in the context of the whole life cycle. Regarding the winemaking process, wine type (White and Red) and style of production influence the result of the different impact categories $[15,16]$. When evaluating the distribution of wine in the US, LCA results can guide the selection of the means of transportation to minimize greenhouse gases [11,17]. Aside from the study of a particular section of the wine production process, some studies evaluate the impact of the whole wine supply chain for Nova Scotia (Canada) [18] and Portugal [19], underlying the influence of pesticide use, glass bottle manufacturing, and transportation on the accumulated impact [20,21].

In this paper, ten environmental impact categories were evaluated through an LCA approach for the case of study of craft wineries in Indiana, USA, as an emerging and non-traditional winemaking area. "Craft Wineries" represent a large number of facilities that fall outside the framework of many regional sustainability programs. The Indiana Wine Region is suitable for LCA analysis of Craft Wineries due to its characteristics of emerging wine region. During the last 30 years, the number of wineries has grown from 9 wineries to more than 116 producing 9 million of liters of wine a year, contributing roughly $\$ 600$ million to the state's economy [22]. The result of the LCA analysis for five supply chain scenarios were normalized and aggregated into the SWSS.

\section{Methods}

Life Cycle Assessment (LCA) is a structured and internationally recognized standardized method to characterized potential environmental impact from the life cycle of a service or product [23]. The ISO 14040/44 families provide the bases for LCA. The ISO 14040 [24] standard provides the principles and framework for LCA, displaying when its application is suitable, and the limitations of the method. The ISO 14044 [25] standard provides the requirements and guidelines for preparing, conducting, reviewing and interpreting an LCA. The standards recognize that an LCA study should include four phases: a

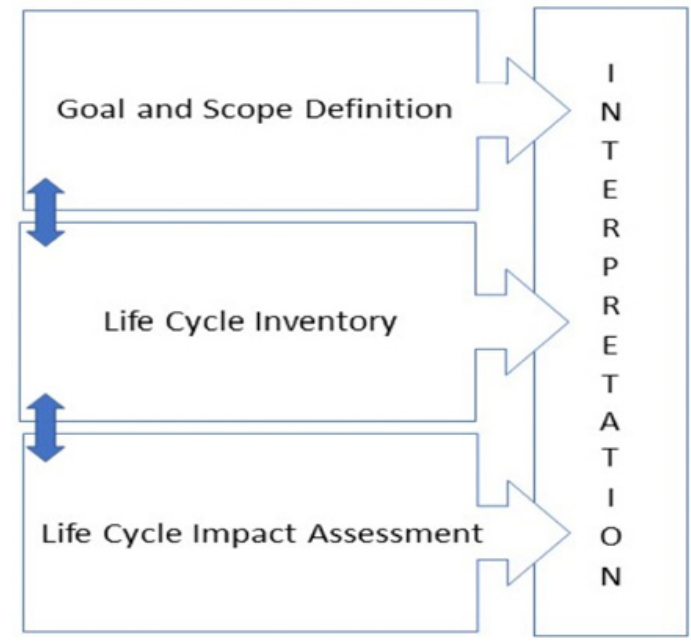

Figure 1. LCA phases according to ISO 14040 [24].

goal and scope definition, an inventory analysis, an impact assessment, and an interpretation of the results (Fig. 1). LCA is recognized as an iterative process; changes in one of the phases may influence and modify the preceding and later phases.

The goal of this study was to perform an LCA following ISO 14040/44 guidelines to quantify environmental impacts as the basis for the definition of an SWSS for different supply chain scenarios for the life cycle of "Craft Wine" made and consumed in Indiana, representing an emerging non-traditional wine region in the United States. We set the functional unit as a bottle of red wine $(0.751)$ and the system boundaries from grape growing to distribution to the point of sale (Fig. 2).

The Life Cycle Inventory (LCI) phase consisted of the systematic data recollection and modeling of the flow of material, energy, and emissions for each life cycle stage within the system boundaries defined. Data collection was performed in two steps. First, information from literature, observations of local wineries, and interviews with winery owners were collected to model the supply chain and processes required for the production of a batch of wine at a representative winery. The batch was defined after the usual business and enologist practice, type and size of equipment, labor required, sourcing of material, energy, and waste management practices.

Secondly, to define the mass, energy and emission balance for each unit process, further interviews and surveys to wine owners were done, and also estimations based on a literature review of wine LCAs $[15,16,18$, 19], Winemaking handbook [26-28], technical equipment sheet, white paper and sectoral business articles. Finally, background data was complete with Ecoinvent v3, AGRIBALYSE v1.3, USLCI, and USA-EI 2.2 dataset.

During the Life Cycle Assessment (LCIA) phase the impact due to the natural resources extracted and the substance emitted to nature are estimated. The results from the LCI were input into SimaPro 8.5 [29] following the TRACI 2.1 /USA 2008 methodology [30]. The ten mid-point impact categories evaluated were "Ozone Depletion," "Global Warming," "Smog," "Acidification," "Eutrophication," "Carcinogenic," "Non-Carcinogenic," "Respiratory Effects," "Ecotoxicity," and "Fossil Fuel Depletion." 


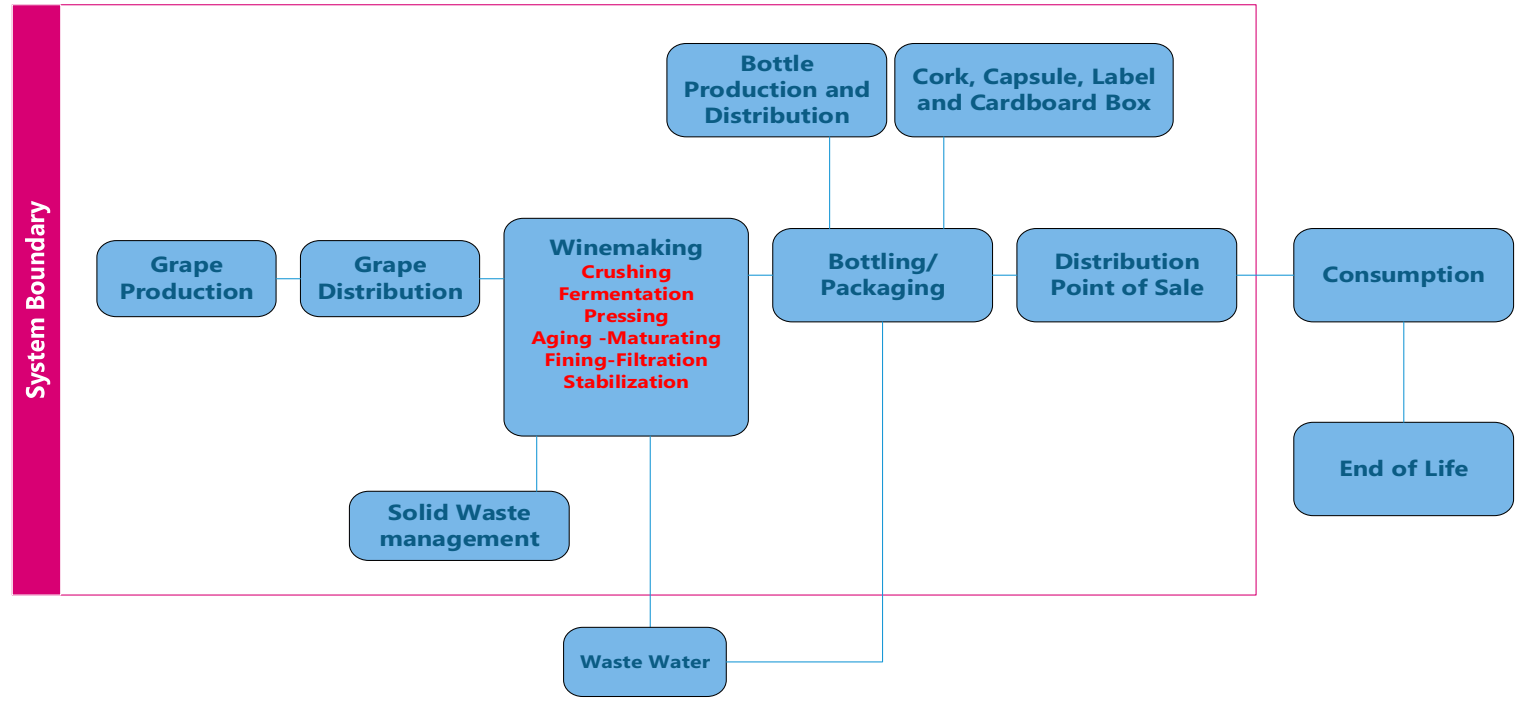

Figure 2. System boundary for supply chain.

Table 1. Scenario description.

\begin{tabular}{|l|l|l|l|l|l|}
\hline $\begin{array}{l}\text { Scenario } \\
\text { Description }\end{array}$ & $\begin{array}{l}\text { Wine } \\
\text { Production }\end{array}$ & $\begin{array}{l}\text { Grape } \\
\text { Origin }\end{array}$ & $\begin{array}{l}\text { Glass Bottle } \\
\text { Manufacturing Origin }\end{array}$ & $\begin{array}{l}\text { Energy Grid } \\
\text { Type }\end{array}$ & $\begin{array}{l}\text { Final Product } \\
\text { Distribution }\end{array}$ \\
\hline IW1 & Indiana & California & USA & Indiana & Indiana \\
\hline IW2 & Indiana & California & CHINA & Indiana & Indiana \\
\hline IW3 & Indiana & California & USA & Indiana & Indiana \\
\hline IW4 & Indiana & Midwest & USA & Cleaner Grid & Indiana \\
\hline IW5 & Indiana & Midwest & USA & Indiana & Indiana \\
\hline
\end{tabular}

These categories describe the potential damage to human health, ecosystem services, and natural resource depletion. We modeled five different scenarios of supply chains that represent different practices for the wine sector in Indiana considering the grape and bottle supplies and the energy grid (Table 1).

Before merging the result from LCIA for each scenario into a single multivariable indicator, it is necessary to normalize the results. The normalization step was performed by transforming the value from each impact into a dimensionless unit by multiplying the result for each effect by a representative factor. For the USA, the normalization factors are defined in TRACI 2.1. and represent the total of emission per capita for each midpoint impact [30].

We constructed the Sustainable Wine Scoring System (SWSS) indicator using Eq. (1). This relationship provides a single value that represents the environmental performance of wine production.

$$
S W S S_{S}=\frac{1}{\sum_{z}^{1} N S_{z}, W_{s}}
$$

The first version of SWSS is obtained dividing one by the summation of the normalized value of each impact category obtained for the FU, multiply by a weight factor. The suffix "s" indicates the name of the scenario under study. $\mathrm{Ns}_{z}$ is the normalized value obtained for each impact category $(\mathrm{z})$, and $\mathrm{W}_{z}$ represents a weighting factor for each impact category. For this first approach, we considered the weighting factor equal to 1 to allow the index to reflect the contribution of each impact to the overall environmental profile of the USA. The weighting factor can be used to reflect some local environmental concern. The higher the value obtained on the SWSS, the lower the environmental impact will be, and the better sustainability performance will be achieved.

Moreover, the alternative version of the SWSS' can be calculated following Eq. (2). The result obtained from this equation represents the average number of bottles produced under each defined scenario that are equivalent to the per capita environmental impact in the USA.

$$
S W S S_{s}^{\prime}=\frac{1}{Z} \sum_{z}^{1} \frac{1}{N S_{z}}, W_{z}
$$

SWSS' is obtained by summating the inverse of the normalized values of each impact category divided by the number of impact categories considered (z). The result obtained represent a weighted average of the number of FU (bottle of wine) equivalent to the annual environmental impact per capita in the USA.

\section{Result and discussion}

The result of the impact assessment for the different supply chain scenarios can be found in Table 2 . The supply chain model with the higher impact in all the midpoint categories is IW2, in which glass bottles are manufactured in China. Impact due to Ozone depletion is more than four times higher for the supply chain scenarios where grape or must needed refrigerate transportation (scenario IW1, IW2, and IW4). In the same manner, these 
Table 2. Impact categories values for each scenario to produce an FU ( 0.751 bottles of wine).

\begin{tabular}{|l|l|l|l|l|l|l|}
\hline & & IW1 & IW2 & IW3 & IW4 & IW5 \\
\hline Impact category & Unit & Total & Total & Total & Total & Total \\
\hline Ozone depletion & $\mathrm{kg} \mathrm{CFC}-11$ eq & $1.30 \mathrm{E}-06$ & $1.30 \mathrm{E}-06$ & $2.37 \mathrm{E}-07$ & $1.29 \mathrm{E}-06$ & $1.30 \mathrm{E}-07$ \\
\hline Global warming & $\mathrm{kg} \mathrm{CO}_{2}$ eq & $2.97 \mathrm{E}+00$ & $3.15 \mathrm{E}+00$ & $1.88 \mathrm{E}+00$ & $2.68 \mathrm{E}+00$ & $1.56 \mathrm{E}+00$ \\
\hline Smog & $\mathrm{kg} \mathrm{O}_{3}$ eq & $2.95 \mathrm{E}-01$ & $4.10 \mathrm{E}-01$ & $1.82 \mathrm{E}-01$ & $2.76 \mathrm{E}-01$ & $1.38 \mathrm{E}-01$ \\
\hline Acidification & $\mathrm{kg} \mathrm{SO}_{2}$ eq & $1.66 \mathrm{E}-02$ & $1.99 \mathrm{E}-02$ & $1.22 \mathrm{E}-02$ & $1.40 \mathrm{E}-02$ & $1.06 \mathrm{E}-02$ \\
\hline Eutrophication & $\mathrm{kg} \mathrm{N}$ eq & $4.68 \mathrm{E}-03$ & $4.90 \mathrm{E}-03$ & $4.14 \mathrm{E}-03$ & $4.45 \mathrm{E}-03$ & $3.92 \mathrm{E}-03$ \\
\hline Carcinogenic & $\mathrm{CTUh}$ & $1.35 \mathrm{E}-08$ & $1.59 \mathrm{E}-08$ & $1.29 \mathrm{E}-08$ & $1.22 \mathrm{E}-08$ & $1.34 \mathrm{E}-08$ \\
\hline Non carcinogenic & $\mathrm{CTUh}$ & $1.18 \mathrm{E}-06$ & $1.21 \mathrm{E}-06$ & $1.13 \mathrm{E}-06$ & $1.17 \mathrm{E}-06$ & $1.08 \mathrm{E}-06$ \\
\hline Respiratory effects & $\mathrm{kg}$ PM2.5 eq & $1.44 \mathrm{E}-03$ & $1.50 \mathrm{E}-03$ & $1.12 \mathrm{E}-03$ & $1.30 \mathrm{E}-03$ & $8.52 \mathrm{E}-04$ \\
\hline Ecotoxicity & CTUe & $1.26 \mathrm{E}+01$ & $1.31 \mathrm{E}+01$ & $1.17 \mathrm{E}+01$ & $1.26 \mathrm{E}+01$ & $1.07 \mathrm{E}+01$ \\
\hline Fossil fuel depletion & MJ surplus & $4.87 \mathrm{E}+00$ & $5.21 \mathrm{E}+00$ & $2.79 \mathrm{E}+00$ & $5.11 \mathrm{E}+00$ & $2.00 \mathrm{E}+00$ \\
\hline
\end{tabular}

Contribution to midpoint per supply chain stage for IW1

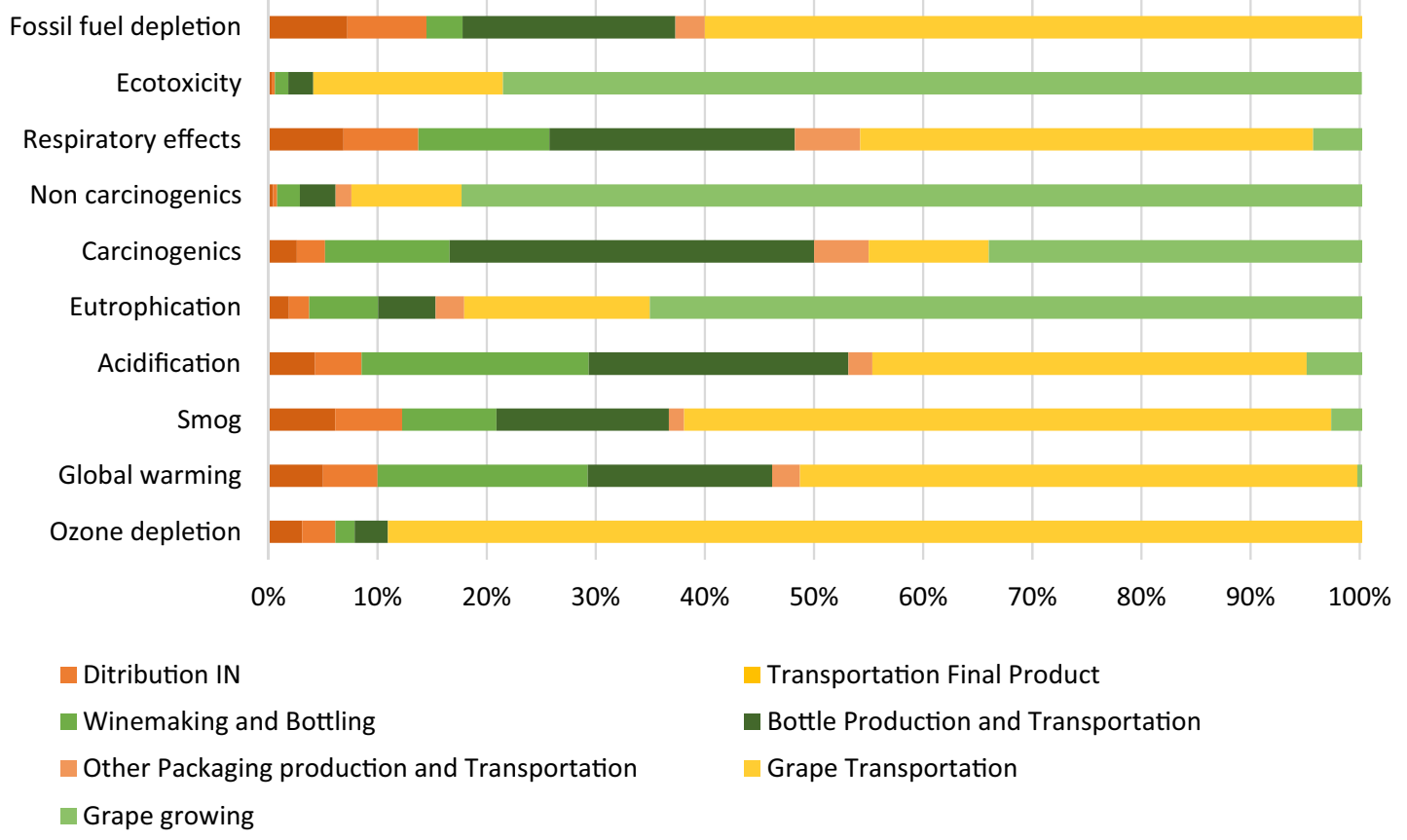

Figure 3. Relative impact contribution of each productive stage for a FU for IW1.

three scenarios almost double IW3 and IW5 regarding Global Warming Potential. The differences among the lower impact scenario and the higher impact scenario for both smog and fossil fuel depletion category reach $60 \%$. Ecotoxicity and Non-Carcinogenic are the midpoint categories that showed less dispersion on the values among the different scenarios. The best performance for all the categories except Carcinogenic is from IW5, the supply chain in which grapes were procured from areas in the Midwest.

Figure 3 presents the relative impact contribution of each productive stage for the reference scenario IW1. On the one hand, grape growing is the major contributor to Non Carcinogenic, Ecotoxicity, Eutrophication and Carcinogenic due to the emission related to fertilizer, pesticide, and herbicide usage. On the other hand, grape transportation is the primary contributor to Ozone Depletion, Global Warming, Smog, Acidification, Respiratory effect, and Fossil fuel depletion. The manufacturing of the glass bottle is the second or third contributor to all the impact with a higher contribution to Carcinogenic, Acidification, Global Warming, and Respiratory effect. For IW1 the contribution in Global Warming potential, Acidification, Carcinogenic and Respiratory effects surpass $10 \%$.

When normalizing the result for each impact category for each scenario (Fig. 4), Non Carcinogenic and Ecotoxicity arise as the midpoint with the highest fraction of emission for a bottle of red wine with a relative value above $0.1 \%$ of the per capita emission in the USA. For Non Carcinogenic, (in reference to IW1), the substance mostly contributing to the impact is Zinc emitted to the soil, follow by Zinc emitted to water and air. For Ecotoxicity, the principal contributor is Cooper to water and soil, and Zinc to water. A substantial portion of this Zinc and Cooper are related to fertilizer and agrochemical usage during the agricultural phase. Strategies involving 


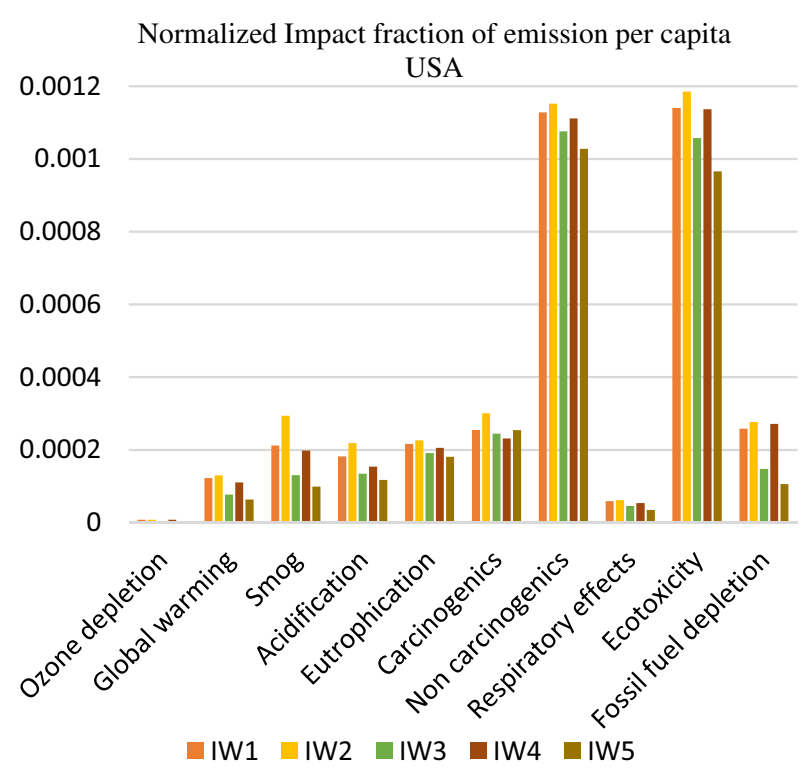

Figure 4. Normalized impact fraction of emission per capita USA.

Table 3. SWSS for Scenario.

\begin{tabular}{|l|l|}
\hline Scenario & SWSS \\
\hline IW1 & 279 \\
\hline IW2 & 259 \\
\hline IW3 & 322 \\
\hline IW4 & 287 \\
\hline IW5 & 351 \\
\hline
\end{tabular}

Table 4. SWSS for Scenario.

\begin{tabular}{|l|l|}
\hline Scenario & SWSS \\
\hline IW1 & 17387 \\
\hline IW2 & 16921 \\
\hline IW3 & 74836 \\
\hline IW4 & 17906 \\
\hline IW5 & 132463 \\
\hline
\end{tabular}

the reduction of this substance will have a higher impact on the normalized environmental profile. The rest of the categories relative impact range between $0.01 \%$ and $0.03 \%$ expect the Respiratory effects and Ozone Depletion which account for less than $0.005 \%$ of emission per capita.

SWSS resulted in the scenarios can be seen in Table 3 . For the five scenarios, the calculated SWSS shows that the scenario IW5 represents the best performance while the scenario IW2 represents the worst performance scenario.

The calculated SWSS' results vary from 16921 bottles equivalent impact for IW2, the scenario with the highest environmental impact, to 132463 bottles equivalent for IW5 the best performance scenario (Table 4). This result can be referenced to the annual USA wine production that is estimated at 3 billion bottles.

Both the SWSS and SWSS' provide with a single indicator of a comprehensive environmental profile of the production of the Functional Unit within the System Boundary proposed. For both versions of the scoring system, the best and worst scenario of supply chain remains the same. For the SWSS' the value obtained have a physical meaning "number of bottles that will produce equivalent environmental impact to the per capita impact in the USA," which is not the case for SWSS.

To adopt the usage of the SWSS as a regional index of sustainability first is necessary to define the product category rule to unify the methodology followed during the LCA of the bottle of wine. Second, a baseline for the SWSS can be calculated through the values obtained from the LCA of a bottle of wine produced on a virtual representative winery designed according to average sizes and technology of the wineries on the region.

Further studies should focus on the validation and robustness of the SWSS. It is necessary to explore uncertainties and sensibility due to the aggregation of the impact categories. Also, is necessary to explore different weigh criteria, in particular, considering the usage of the regional carrying capacity. Moreover, an analysis of the social LCA methodologies will be a review to define the proper aggregation of social indicators into the SWSS. In relation to consumer awareness and the integration of SWSS on the label, a controlled experiment will be useful to understand the comprehension of a numeric scoring system as a representation of sustainability attribute in a bottle of wine. Then a buying behavior analysis will be completed to define the optimum location of the SWSS on the wine packaging to increase the perceived value of the final product.

\section{Conclusion}

In the road of building a single indicator that genuinely represents the environmental performance of wine production, LCA and its midpoint categories allow the understanding of the environmental profile considering the whole life cycle environmental profile of the wine. LCA impact categories can be normalized by the local characteristic of a region to define which impact is the one that the wine industry is a higher contributor. A weighting factor can multiply each normalized impact to obtain a Sustainable Wine Scoring System (SWSS). The SWSS has the potential to represent sustainable attributes of wine in a more suitable way than a single isolated indicator such as carbon footprint.

Even when this initial version has limitations, it emerges as a promising methodology, as it can integrate social and economic metrics to support decision-making while facilitating communication with consumers and stakeholders. Quantifying environmental impact enables to set targets and evaluate the cost of improvement under different propose solutions. Evaluating different scenarios with a complimentary cost analysis allow deciding on the economically sound solution for reducing environmental impact. Thereby, identifying the which are the most suitable practice to follow according to its own sustainable strategy. Finally, if successfully integrate into the label, it will allow the consumer to easily identified sustainable attribute to make an informed decision. Thus, facilitating the evaluation of the value-add by sustainable attribute for the wine industry.

This study is being developed thanks to funding from the OIV research Grant 2017/2018. 


\section{References}

[1] T.O. Olawumi, D.W.M. Chan, J. Clean. Prod. 183, 231 (2018)

[2] M.R. Mozell, L. Thach, Wine Econ. Policy 3, 81 (2014)

[3] P. Mora, Wine Positioning (Cham: Springer International Publishing, 2016)

[4] K. Loveless, S. Mueller, L. Lockshin, A. Corsi, "The relative importance of sustainability, quality control standards and traceability for wine consumers: a cross-national segmentation," p. 1 (2010)

[5] Wine Institute, Natural Marketing Institute, and PE International, "Wine Trade and Consumer Survey on Sustainable Winegrowing," (2013)

[6] B. Klohr, R. Fleuchaus, L. Theuvsen, Proc. 8th Int. Conf. Acad. Wine Bus. Res., 28 (2014)

[7] R. McMillan and Silicon Valley Bank, "State of the Wine Industry 2017' (2017)

[8] G. Zucca, D.E. Smith, D.J. Mitry, Int. J. Wine Res. 1, 189 (2009)

[9] E. Ginon, G. Ares, L.H.E. dos S. Laboissière, J. Brouard, S. Issanchou, R. Deliza, Food Res. Int. 62, 837 (2014)

[10] B. Rugani, I. Vázquez-Rowe, G. Benedetto, E. Benetto, J. Clean. Prod. 54, 61 (2013)

[11] T. Colman, P. Päster, "Red, White and 'Green': The cost of carbon in the global wine trade" (2007)

[12] P. Villanueva-Rey, I. Vázquez-Rowe, M.T. Moreira, G. Feijoo, J. Clean. Prod. 65, 330 (2014)

[13] A.C.I. Pizzigallo, C. Granai, S. Borsa, J. Environ. Manage. 86, 396 (2008)

[14] K.L. Steenwerth, E.B. Strong, R.F. Greenhut, L. Williams, A. Kendall, Int. J. Life Cycle Assess. 20, 1243 (2015)

[15] R. Iannone, S. Miranda, S. Riemma, I. De Marco, J. Clean. Prod. 111, 172 (2016)

[16] B. Notarnicola, G. Tassielli, G.M. Nicoletti, Life cycle assessment (LCA) of wine production (Woodhead Publishing Limited, 2003)
[17] C. Reich-Weiser, P. Paster, C. Erickson, D. Dornfeld, J. Wine Res. 21, 197 (2010)

[18] E. Point, P. Tyedmers, C. Naugler, J. Clean. Prod. 27 11 (2012)

[19] B. Neto, A.C. Dias, M. Machado, Int. J. Life Cycle Assess. 18590 (2013)

[20] M. Meneses, C.M. Torres, F. Castells, Sci. Total Environ. 562, 571 (2016)

[21] L. Petti et al., Life Cycle Assessment in the Agrifood Sector (Wine Sector Chap3), no. January. 2015

[22] A.F. Rimerman and + Co. LLP, "The Economic Impact of indiana Wine and Wine Grapes -2016" (2017)

[23] G. Benedetto, G.L. Corinto, B. Rugani, "The evolution of Life Cycle Assessment (LCA): some guidelines for future research in the wine sector," in 50th Annual SIDEA Conference, At Lecce Italy 1, 1 (2013)

[24] International Organization for Standardization (ISO), "ISO 14040 Environmental management - Lifa cycle assessment - Principles and framework" (2006)

[25] International Organization for Standardization (ISO), "ISO 14044-2006c Environmental Management-Life Cycle Assessment - Requirements and Guide- lines" (2006)

[26] M. Smyth, J. Russell, T. Milanowski, Solar energy in the winemaking industry (Springer, 2011)

[27] C.E. Butzke, Winemaking problems solved (CRC Press, 2010)

[28] A.G. Reynolds, A. Gordon, Viticulture and wine quality (Oxford; Boca Raton: CRC Press, 2010)

[29] PRé Consultants, "SimaPro 8.5." (2017)

[30] United States EPA, Office of Research and Development and Sustainable Technology Division, "Tool for the Reduction and Assessment of Chemical and Other Environmental Impacts (TRACI) TRACI version 2.1 User's Guide" (2012) 